\title{
The Role of Recombinant Human Growth Hormone Biosimilars in the Management of Growth Disorders
}

\author{
Tomasz E Romer
}

Endocrinologist, Private Practice, Warsaw DOI:10.17925/EE.2009.05.00.47

\begin{abstract}
Since ancient times plant and animal tissues have been used as medicines. In the 20th century growth hormone as a purified extraction from human pituitaries was still used to treat growth disorders. Since the genetic engineering of host cells became possible, a new generation of medicines obtained using recombinant DNA (rDNA) technology has emerged. These medicines have been named 'biopharmaceuticals'. The first biopharmaceutical growth hormones were patented in the 1980s, so already over two decades of clinical experience support the development of a new, off-patent growth hormone preparation obtained by rDNA technology. The European Medicines Agency (EMEA) has put in place a centralised procedure for the approval of new biopharmaceuticals. This procedure includes testing comparability with a reference product and demands post-approval pharmacovigilance. Omnitrope ${ }^{\circledR}$ was the first off-patent recombinant human growth hormone (rhGH) approved on the basis of the biosimilar pathway; it underwent a very demanding approval procedure in 2006 and is now used for several indications in Europe, the US, Canada, Japan, Australia and other countries where it has received marketing approval.
\end{abstract}

\section{Keywords}

Off-patent biopharmaceuticals, growth hormone, Omnitrope ${ }^{\circledR}$, EMEA centralised procedure, biosimilars, recombinant DNA (rDNA) technology, biologics, recombinant human growth hormone (rhGH), somatropin

Disclosure: Tomasz E Romer receives consulting fees from Sandoz.

Received: 13 July 2009 Accepted: 5 August 2009

Correspondence: Tomasz E Romer, ul Gardenii 8, 04-649 Warsaw, Poland. E: tomasz@romer.pl

\section{Biologics}

Biological medicines have been used since ancient times and are plant-derived. Healing plants were grown next to the temples of the ancient Egyptians and herbs to which therapeutic properties are attributed are still cultivated today. Phytotherapy still plays a considerable role in healthcare, although the safety and efficacy of applied herbal medicine procedures have not been proved using modern methods from evidence-based medicine. Animal tissue extracts are still used as biological medicine. More than 100 years ago it was found that pituitary extracts affect growth. Maurice Raben first isolated pituitary human growth hormone (pit-hGH) from human pituitaries collected at autopsy (1951) and used it in GHdeficient patients (1958). Soon afterwards, a period of therapeutic use of pituitary-derived hGH, which has lasted for more than 20 years, began.

In the late 1970s, after many years of scientific research into DNA technology, the techniques of cutting at specific sites and replicating and synthesising DNA molecules greatly improved, and inserting specific DNA into bacterial or mammalian cells became possible. The host cell replicates inserted DNA in a natural way and synthesises the protein coded by the DNA. From that time on, it was possible to obtain active components of complex high-molecular-weight molecules for medical purposes. Continuous development of analytical methods and biological assays improved biotechnology methods, and thus an increasing number of complex molecules could be produced. Industrial manufacturing started in the early 1980 s by cultivating genetically modified micro-organisms or cells, which was followed by purification of an active ingredient. Soon several important new drugs were patented; drugs obtained using this technique were called 'biopharmaceuticals' (see Figure 1). Insulin and $\mathrm{GH}$ were the first human hormones to be produced this way. ${ }^{1}$

\section{Biopharmaceuticals}

The first biopharmaceuticals were soon introduced to the market without specifically designed regulatory procedures for approval. However, after $>20$ years of their use for various indications, there is extensive clinical experience and their safety and efficacy profile is well known.

In 2001, the first patents protecting biopharmaceuticals expired. Over a period of several years and in keeping with technology development, the European Drug Agency (EMEA) developed a new legislation regulatory pathway for off-patent biopharmaceuticals. The procedures used for the approval of generics did not protect adequately against possible pitfalls in the sophisticated production and purification of biopharmaceuticals. The difference between generics and off-patent biopharmaceuticals is shown in Table 1.

The new regulatory pathway for approving technologically advanced medicinal products such as biopharmaceuticals was implemented in 2004 as the so-called 'centralised procedure'. This means that the application for marketing authorisation must not go 
Figure 1: Biopharmaceuticals - A New Era of Biologics

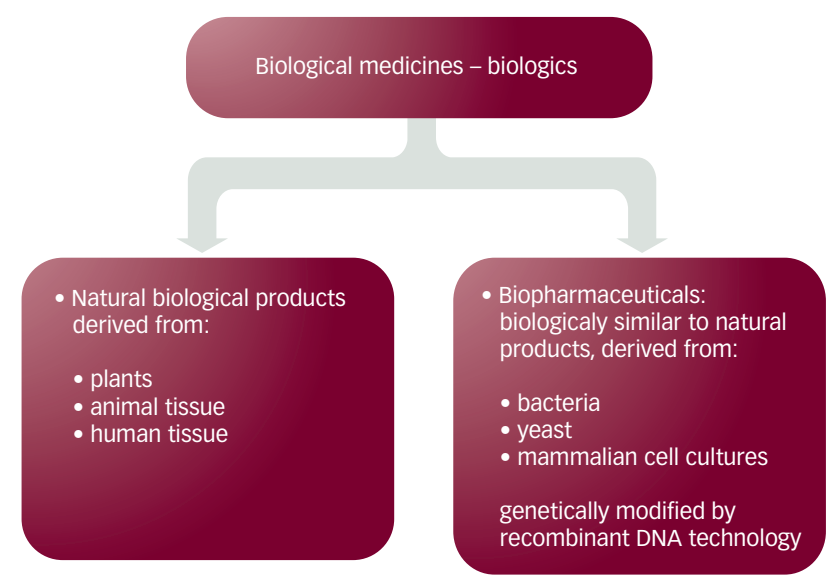

Table 1: The Difference Between Generics and Off-patent Biopharmaceuticals

\begin{tabular}{|c|c|c|}
\hline Features & Generics & $\begin{array}{l}\text { Off-patent } \\
\text { Biopharmaceuticals } \\
\text { ('Biosimilars') }\end{array}$ \\
\hline Molecular weight & Up to $5 \mathrm{kDa}$ & up to $500 \mathrm{kDa}$ \\
\hline Production & Chemical synthesis & $\begin{array}{l}\text { Recombinant DNA } \\
\text { technology }\end{array}$ \\
\hline $\begin{array}{l}\text { Comparability with the } \\
\text { reference product: what } \\
\text { should be demonstrated? }\end{array}$ & $\begin{array}{l}\text { Bioequivalence on } \\
\text { absorption }\end{array}$ & $\begin{array}{l}\text { Bioequivalence in: } \\
\text { - physicochemical } \\
\text { characterisation } \\
\text { - biological } \\
\text { characterisation } \\
\text { - pre-clinical } \\
\text { - PK/PD } \\
\text { - clinical safety } \\
\text { and efficacy }\end{array}$ \\
\hline
\end{tabular}

$P K=$ pharmacokinetics; $P D=$ pharmacodynamics.

through local regulatory authorities, but rather must follow the centralised way laid down by the EMEA.

EMEA proposed the new name for off-patent biopharmaceuticals: 'similar biological medicinal products' or 'biosimilars'. In the opinion of the author of this article, the name is misleading. There is no common understanding (and cannot be) that 'biosimilar'

Over a period of several years and in keeping with technology development, the European Drug Agency developed a new legislation regulatory pathway for off-patent biopharmaceuticals.

describes a regulatory pathway and is a regulatory term, and it does not mean that this new product is a different, yet similar, medicine. The first approved biosimilar medicinal product was approved more than three years ago. It was the rhGH Omnitrope ${ }^{\circledR}$ and there is still a lot of misunderstanding concerning the drug among doctors and patients. To avoid confusion, the wording should be more similar to that used in the US, which is clearer 'follow-on protein product' (FOPP), proposed by the US Food and Drug Administration (FDA) or 'subsequent entry biologic' (SEB), proposed by Health Canada.

Nevertheless, Europe is the worldwide leader in the development of a robust regulatory framework. As a consequence, pharmaceutical

$$
\begin{aligned}
& \text { In the critical year of } 1985, \text { almost } 100 \\
& \text { children in clinical trials received DNA } \\
& \text { recombinant methionyl growth hormone } \\
& \text { (rhGH), and soon after the US Food and } \\
& \text { Drug Administration approved rhGH } \\
& \text { for clinical use. }
\end{aligned}
$$

development in this new area has been gaining pace since 2004. The EU term 'biosimilar' medicine means that it has been compared with and demonstrated that it matches the reference product in terms of quality, safety and efficacy.

\section{Biopharmaceutical Growth Hormone} The Reference Product

The revolutionary new technology of recombinant DNA (rDNA) has come just in time, as the supply of insulin obtained from animal sources was barely sufficient to meet the demands of the rapidly growing global population of patients with diabetes. However, the story of GH was more dramatic. In 1985, >25 years after the first patient had received pit-hGH, four young adult patients developed Creutzfeldt-Jakob disease. All of these patients had been receiving pithGH for many years. After intensive investigation, it became obvious that the pituitary glands used for the extraction of $\mathrm{GH}$ administered to these patients were most probably collected from individuals with creutzfeldt-Jakob disease and were contaminated with slow viruses. ${ }^{2}$

The first production of $\mathrm{GH}$ with the use of genetically modified Escherichia coli by Genentech Inc. was reported in 1977. In the critical year of 1985, almost 100 children in clinical trials received DNA recombinant methionyl $\mathrm{GH}(\mathrm{rhGH}){ }^{3,4}$ and soon after the US FDA approved rhGH for clinical use. In Europe, in $1981 \mathrm{Kabi}$ Vitrum Sweden bought the technology and after short clinical trials carried out in Sweden, ${ }^{5}$ the UK ${ }^{6}$ and Germany ${ }^{7}$ rhGH was approved for clinical use. Kabi Pharmacia, the successor of Kabi Vitrum, launched the Kabi International Growth Study (KIGS), which corresponded to pharmacovigilance, which is now routine for newly developed biopharmaceuticals. The name of the study was not changed when Kabi became Pharmacia and then Pfizer. Currently, KIGS has been running for more than 20 years and data for more than 50,000 patients treated with $\mathrm{GH}$ have been collected in its database. It is an important source of knowledge for clinicians and scientists. ${ }^{8}$ Data gained provided the background for the EMEA decision to indicate Genotropin ${ }^{\circledR}$ as the reference product for assessing clinical comparability in pre-registration studies.

\section{Recombinant DNA Biotechnology - Benefits and Hazards}

The insertion of DNA encoding for the desired protein, e.g. hGH, into the host cell genome, either directly or using a plasmid as a vehicle, 
is an important step in rDNA biotechnology of rhGH. The host cell transcribes and translates the inserted DNA to produce the protein, e.g. GH, of identical sequence to pit-hGH. Host cells are multiplied to create a master cell bank (MCB). For each biopharmaceutical a batch of manufactured host cells is taken from the MCB to create working cell bank (WCB). The WCB is cultivated in a bioreactor, where cells proliferate and produce $\mathrm{GH}$. In the next step cells are harvested and recombinant hGH is isolated and purified. The final steps lead to the prouduction of a ready-to-use cartridge of GH by aseptic filling and finishing using state-of-the-art technologies.

Biotechnology opened a door to the treatment of diseases that previously would not be treated adequately or at all. For example, for hGH therapy it was necessary to extract pit-hGH from human pituitary glands. Thus, only few patients worldwide could be treated, with all the risks of infections via the extracted hormone. Thanks to rhGH, supply is no longer limited and there is no risk of infections, such as Creutzfeldt-Jakob disease.

Recombinant biopharmaceuticals are produced by living cells, and as all biologics have the capacity to induce immune responses in the human body. The development of neutralising antibodies can cause life-threatening serious adverse events in contrast to antibodies that are not neutralising, such as those for $\mathrm{rhGH}$, which do not seem to have any negative effects on safety or on efficacy.

The progress of scientific evaluation

of biopharmaceuticals and possibilities

for additional characterisation through

physico-chemical analysis, as well

as in vivo and in vitro bioassays,

are still expanding.

The immunogenic safety of biologics can only be determined in clinical trials and, to a limited extent, in specifically developed biological tests. In addition, long-term post-marketing surveillance studies have become a standard for all biologics. This is the reason for applying special measures for safety, i.e. the biosimilar regulatory pathway of the EMEA.

\section{Omnitrope}

Omnitrope is the first off-patent biopharmaceutical to receive market approval according to EMEA centralised procedures. Regulatory criteria for approval were designed to prove comparability with a reference product, Genotropin, which is registered in the EU. The dossier of EMEA regulatory requirements takes into consideration, among others, comprehensive analysis of physico-chemical protein properties. Over the past two decades progress in analytical techniques has been key to making the development of off-patent biopharmaceuticals possible.

Today's analytical technologies enable in-depth investigation of al relevant properties of a recombinant protein or glycoprotein regarding its primary, secondary, tertiary and quaternary structures, allowing direct and thorough comparison of the quality and characteristics of biopharmaceuticals. The progress of scientific
Figure 2: Mean Height Velocity Standard Deviation Scores - Omnitrope versus Genotropin

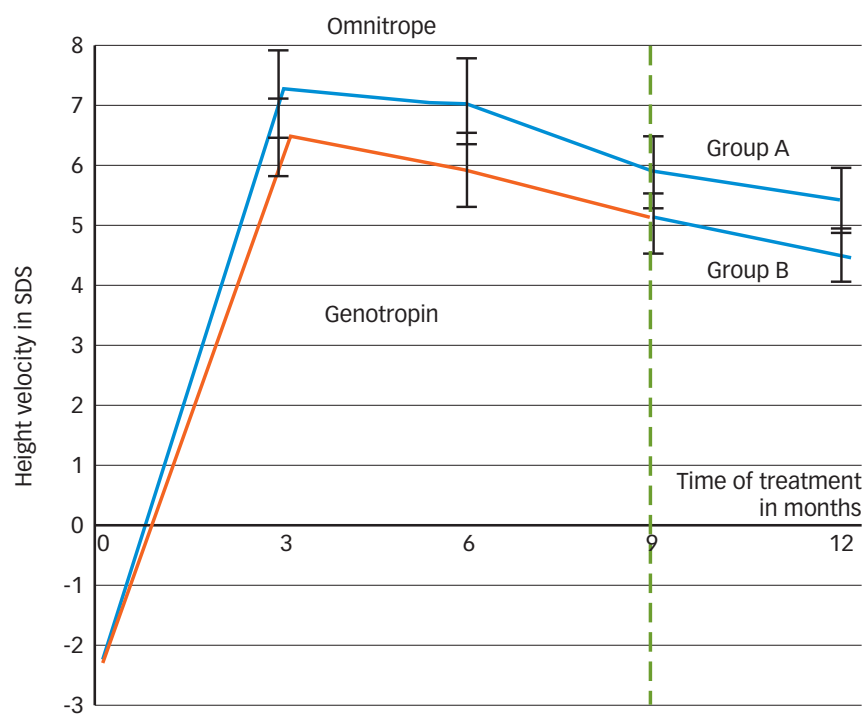

Height velocity (HV) given in standard deviation scores (SDS) for 89 pre-pubertal children randomised to group $A\left(n=44\right.$, Omnitrope $\left.{ }^{\circledR}\right)$ and group $B\left(n=45\right.$, Genotropin $\left.{ }^{\circledR}\right)$ before the treatment and after three, six and nine months of treatment. After nine months, group $B$ patients were switched to Omnitrope. HV data were very similar between group $A$ and group $B$ throughout the study: the differences in the mean was not significant at any of the timepoints. HV at month 12 showed that the treatment response was not affected by switching from Genotropin to Omnitrope.

\section{Figure 3: Height Velocity - Ninth Month of Treatment}

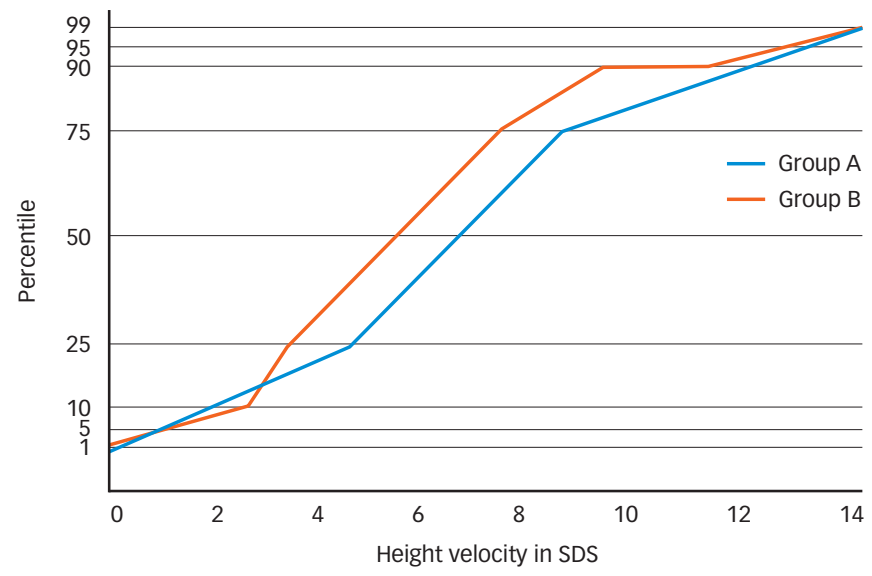

The distribution of height velocity (HV) standard deviation scores (SDS) in patients from group $A$ and $B$ after nine months of the treatment is presented. About $80 \%$ of the patients showed an average growth response of between two and eight SDS. In both groups there was $10 \%$ good and poor responders. In all patients, independently of the magnitude of the response, the rate of HV SDS was similar in both groups. This shows a consistency of growth response between Omnitrope ${ }^{\circledR}$ and Genotropin ${ }^{\circledR}$ in the treated population of pre-pubertal growthhormone-deficient (GHD) children.

evaluation of biopharmaceuticals and possibilities for additional characterisation through physico-chemical analysis, as well as in vivo and in vitro bioassays, are still expanding. Dossiers for 'biosimilar' medicines also include pre-clinical data generated through programmes of in vitro and in vivo tests (including animal testing) that compare the pharmacodynamic (PD) properties, toxicity studies and studies regarding any specific safety concerns, such as local tolerance. Comparative phase I studies are designed in a way that allows for exploring the absorption and elimination characteristics of both the reference product and the new biopharmaceutical. Differences in manufacturing processes and expression systems and 


\section{Pituitary Disorders}

changes to the manufacturing process due to increasing production scale, improving product stability or moving production to another site must not change the comparability level. A manufacturer must provide evidence that the procedural changes did not adversely affect the quality of the product.

The final 'comparability exercises' include the clinical phase III study. The aim of the phase III clinical study was to compare omnitrope with the reference product and to assess its long-term safety and efficacy. To meet this aim, a population of 89 children with idiopathic GH deficiency diagnosed in accordance to the worldwide accepted criteria were randomised to Omnitrope group A $(n=44)$ or Genotropin group B $(n=45)$. The patients were GH-naive.

\author{
The process of developing Omnitrope \\ was planned to fulfil the rigorous \\ demands of the EMEA centralised \\ registration procedure.
}

In the study, a lyophilised Omnitrope formulation was used, as the reference product was of the same formulation. The study comparing Omnitrope with the reference product was carried out for nine months; the first six months is the period of treatment with the most intense growth response to $\mathrm{GH}$ - the so-called catch-up period. Moreover, selected GHD-naïve pre-pubertal children were the population most sensitive to $\mathrm{GH}$. A study planned in this way is considered to be the best model to detect any differences between $\mathrm{GH}$ preparations. Randomised groups were similar for all auxological parameters before the treatment was started. There were no significant statistical differences between the groups in any of the time-points assessed during the treatment period (three, six and nine months of the treatment; see Figures 2 and 3). Adverse reactions observed in patients did not differ between the groups.

To assess the long-term safety and efficacy of both formulations of Omnitrope - the lyophilised and the more convenient ready-to-use liquid formulation - the study of the same group of patients was continued for up to seven years. ${ }^{9,10}$ Results showed that in terms of safety profile and efficacy, Omnitrope was therapeutically similar to Genotropin and, according to the data from literature, to other preparations of rhGH such as Saizen and Norditropin. ${ }^{11-17}$

\section{Conclusion}

The process of developing Omnitrope was planned to fulfil the rigorous demands of the EMEA centralised registration procedure. It has created an opportunity to excel in the production of high-quality biopharmaceuticals.

In the past 25 years significant advances in analytical technology have been seen. These have allowed the establishment of new comparability assessments for comparison of the new version of biopharmaceutical to the reference product. The consistency and comparability of Omnitrope with the reference product in terms of physicochemical protein structure, biological activity, toxicity and tolerance have been proved in pre-clinical studies. Similar PK, PD and safety profiles to the reference product in phase I clinical studies have been proved. Long-term phase III clinical studies have demonstrated therapeutically comparability with the reference product, clinical efficacy and safety, as well as low immunogenicity.

Therefore, Omnitrope, being fully similar to the reference product, is approved in Europe for a wide range of indications: GH deficiency in children and adults, Turner syndrome, chronic renal insufficiency, children small for gestational age and Prader-Willi syndrome. Patients living in Europe, the US, Canada, Japan, Australia and all other countries where Omnitrope has received marketing approval have gained a new valuable, more affordable recombinant hGH.

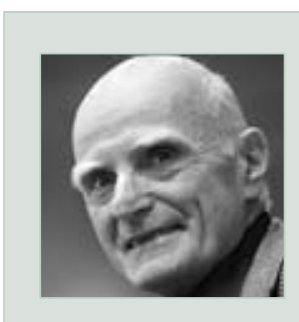

Tomasz E Romer is an endocrinologist in private practice in Warsaw. Prior to this he was Head of the Department of Endocrinology at the Child Health Memorial Research Institute in Warsaw, where he also founded a Paediatric Endocrinology Unit. Professor Romer has been a member of the European Society of Paediatric Endocrinology since 1985 and was President and organiser of the 38th Annual Meeting in Warsaw in 1999. He has also been principal investigator in the pre-registration clinical trials of Maxomate (Sanofi), Accretropin (Cangene), Valtropine (Biopartners) and Omnitrope (Sandoz). Professor Romer obtained his PhD in 1964 and his professorship in 1985
1. Miller WL, Baxter JD, Recombinant DNA - a new source of insulin, Diabetologia, 1980;18:431-6.

2. Dean $\mathrm{HJ}$, Friesen $\mathrm{HG}$, Growth therapy in Canada: end of one ere and beginning of another, Can Med Assoc J, 1986;135:297-301.

3. Takano K, Shizume K, Hizuka N, et al., Treatment of idiopathic pituitary dwarfism with methionyl human growth hormone, Endocrinol Jpn, 1983;30:523-7.

4. Kaplan SL, Undrewood LE, August GP, et al., Clinical studies with recombinant-DNA-derived methionyl human growth hormone in growth hormone deficient children, Lancet, 1986;1:697-700.

5. Girard F, Gourmelen M, Clinical experience with Somatonorm, Acta Paediatr Scand Suppl, 1986;325:29-32.

6. Milner RD, Clinical experience of somatrem: UK preliminary report, Acta Paediatr Scand Suppl, 1986;325: 25-8

7. Bierich JR, Treatment of pituitary dwarfism with biosynthetic growth hormone, Acta Paediatr Scand Suppl, 1986;325:13-18.

8. Ranke MB, Wilton P (eds), Growth Hormone Therapy in KIGS -
10 Years' Experience, Heidelberg, Leipzig: Johann Ambrosius Barth Verlag, 1999.

9. Romer T, Peter F, Saenger P, Starzyk J, Koehler B, Korman E, Walczak $M$, Efficacy and safety of a new ready-to-use recombinant human growth hormone solution, $J$ Endocrinol Invest, 2007;30:578-89.

10. Romer T, Saenger P, Peter F, et al., Seven years of safety and efficacy of the recombinant human Growth Hormone Omnitrope ${ }^{\circledR}$ in the treatment of Growth Hormone Deficient children: results of a phase III study, Hormone Res, 2009; in press.

11. Coste J, Letrait M, Carel JC, et al., Long-term results of growth hormone treatment in France in children of short stature: population, register based study, BMJ, 1997; 315:708-13.

12. Cohen P, Bright GM, Rogol AD, et al., Effects of dose and gender on the growth and growth factor response to $\mathrm{GH}$ in GH-deficient children: implications for efficacy and safety, I Clin Endocrinol Metab, 2002;87:90-98.

13. Vicens-Calvet E, Cuatrecasas-Membrado JM, Spanish multicentre trial of recombinant somatropin. Spanish
Collaborative Group, Acta Paediatr Scand Suppl, 1988;347:180-83.

14. De Muinck Keizer-Schrama S, Rikken B, Hokken-Koelega A, et al., Comparative effect of two doses of growth hormone for growth hormone deficiency. The Dutch Growth Hormone Working Group, Arch Dis Child, 1994;71: 12-18.

15. Bercu BB, Murray FT, Frasier SD, et al., Long-term therapy with recombinant human growth hormone (Saizen) in children with idiopathic and organic growth hormone deficiency, Endocrine, 2001;15:43-9.

16. Root AW, Kemp SF, Rundle AC, et al., Effect of long-term recombinant growth hormone therapy in children-the National Cooperative Growth Study, USA, 1985-1994, J Pediatr Endocrinol Metab, 1998;11:403-12.

17. Reiter EO, Price DA, Wilton $P$, et al., Effect of growth hormone (GH) treatment on the near-final height of 1258 patients with idiopathic GH deficiency: analysis of a large international database, J Clinl Endocrinol Metab, 2006;91:2047-54. 